\title{
Barriers and Promoting Strategies to Sexual Health Assessment for Patients with Coronary Artery Diseases in Nursing Practice: A Literature Review
}

\author{
Izzeddin A. Abu Bdair ${ }^{*}$, Rose E. ConsTantino ${ }^{2}$ \\ ${ }^{1}$ School of Nursing, The University of Jordan, Amman, Jordan \\ ${ }^{2}$ School of Nursing, University of Pittsburgh, Pittsburgh, Pennsylvania, USA \\ Email: *Izzaden_1986@yahoo.com, roc100@pitt.edu
}

How to cite this paper: Bdair, I.A.A. and ConsTantino, R.E. (2017) Barriers and Promoting Strategies to Sexual Health Assessment for Patients with Coronary Artery Diseases in Nursing Practice: A Literature Review. Health, 9, 473-492.

https://doi.org/10.4236/health.2017.93034

Received: January 12, 2017

Accepted: March 21, 2017

Published: March 24, 2017

Copyright $\odot 2017$ by authors and Scientific Research Publishing Inc. This work is licensed under the Creative Commons Attribution International License (CC BY 4.0).

http://creativecommons.org/licenses/by/4.0/

\begin{abstract}
Background: Sexual health is an important and integral part of human health. Patients often voice their concerns regarding their sexual health after experiencing coronary artery diseases. Nurses face many barriers to conduct sexual health assessment. Although many sexual health instructions have been developed, nurses still pay little attention to sexual health assessment. Purpose: The purpose of this literature review was to identify the barriers and strategies that promoted sexual health assessment in clinical nursing practice. Design: A comprehensive search of the recent literature related to barriers and promoting strategies to sexual health assessment was undertaken. Methods: A review of literature published over the last 10 years on a wide variety of recent studies in nursing and related discipline in the field of sexual health was performed. Findings: Most studies indicated that sexual health was poorly addressed in clinical settings. Barriers to addressing sexual health are multifactorial; we classified them into four categories: patients related barriers, nurses related barriers, organizational related barriers and value related barriers. Many strategies to enhance sexual health assessment and counseling in clinical setting are summarized. Conclusion: Overall, it is evident that nurses encounter many barriers to sexual health assessment. Therefore, investigating these barriers and developing appropriate interventions are recommended.
\end{abstract}

\section{Keywords}

Sexual Health, Barriers, Nurses, Jordan, Coronary Artery Diseases

\section{Introduction}

Sexual health is a major health need and concern for patients recovering from 
major diseases and disorders. Sexuality is a central component of all human functions that need to be fulfilled. The World Health Organization defined sexual health as "a state of physical, emotional, mental and social well-being in relation to sexuality; it is not merely the absence of disease, dysfunction or infirmity" [1]. Sexual activity is defined as "any mutually voluntary activity with another adult person that involves sexual contact, whether or not intercourse or orgasm occurs" [2]. Sexual activities include various behaviors for example kissing, hugging, touching, stimulating and intercourse [3]. Sexual dysfunction is a broad term that reflects any problem which interferes with persons' sexual desire [4]. Sexual dysfunction includes erectile dysfunction, loss of sexual desire, orgasmic difficulties, lack of interest in sex, and feeling afraid by patients or by the partner in having sex [5].

Heart diseases are still the number one cause of death in United States and developed world [6]. Annually about 750,000 Americans have a heart attack [7]. In Jordan, heart diseases account for more than $35 \%$ of the deaths among Jordanian population [8].

\section{The CADs and Sexual Health}

The experience of living with CADs is associated with a variety of consequences that influence patients' sexual health [9]. Patients with CADs complain of different sexual health problems including decrease of sexual activities, interest in sex and level of sexual satisfaction [10], physical discomfort during sexual activities [11], and alterations in both frequency and quality of sexual activity [12].

There are many factors that affect sexual health of patients with CADs. Miner and Kim reported that aging, being a male, and having chronic diseases create a negative effect on sexual health [13]. Other factors include comorbidities [14] and associated symptoms such as anxiety and fatigue [15]. The new role of partners in taking care of their spouse instead of engaging in sexual activities also affects patients' sexual health [16]. Jaarsma and colleagues reported that patients' activity intolerance, physiological and psychological changes due to health condition, treating medications and recreational habits influence patients' sexual health [15].

The prevalence of sexual problems is high among patients with CADs. The rates of sexual health problems vary based on a variety of related factors such as patient's age, severity of disease and co-morbidities that range between 20\% [17] and $70 \%$ [18]. About half (46\%) of 382 patients with CADs in six rehabilitation centers reported sexual problems [19]. In one study conducted in Jordan $(\mathrm{N}=$ 124), about three quarters of patients with heart diseases reported that their sexual health is being altered [20].

The purpose of this literature review was to identify the barriers and strategies that promote sexual health assessment in clinical nursing practice. In Jordan, there is little research done in the field of sexual health in nursing. The findings may help direct further research and lead to practical interventions for nursing practice. At the heart of this review, the research question is: what are the barriers and prompting strategies to sexual health assessment in clinical nursing 
practice?

\section{Methods}

A thorough and exhaustive review of related literature was conducted to analyze and synthesize the literature about barriers and promoting strategies to sexual health assessment in nursing clinical practice. The literature search was conducted by the first author through searches of the following electronic databases: PubMed, Medline, science direct, EBSCO, Google Scholar and CINALH. The search strategy used different key words including sexual health, nurse's knowledge, barriers, CADs and sexual counseling on a wide range of quantitative and qualitative studies about sexual health assessment in clinical practice. Reference lists of reviewed studies were retrieved to identify additional and relevant studies that were not found through any other search methodologies in electronic databases.

The inclusion criteria were published studies in English language, relevance to the study aims, published within the last 10 years. The exclusion criteria were studies that were not relevant to the study purposes, non-nursing studies, and studies published in languages other than English or before more than 10 years. All obtained articles were filtrated to remove irrelevant and duplicated articles. The process of the articles extraction was selective; the studies that examined barriers or promoting interventions to sexual health assessment in nursing were selected from different cultural backgrounds. The final included studies in the study sample were 19.

\section{Background}

\subsection{Patients' Needs for Sexual Health Assessment}

According to the American Heart Association, fulfilling sexual activity is an important aspect of the quality of life [21]. Patients with CADs are eager to return to their routine after discharge. However, resuming sexual activities is viewed as a challenging activity by patients and their partners [22]. Miner and Kim found that men and their partners have a great concern when they can resume sexual activity safely after CADs [13]. For example, patients may need to know how their sexual health is being affected by the illness, by medications and associated side effects, when can they resume their sexual activities, what are the warning signs reportable to the physician, what sex enhancing medications can they use and what preparations are available to aid in resuming sexual activities. Byrne and colleagues reported that about half of 382 cardiac patients preferred the opportunity of addressing their sexual health concerns by health care providers [19]. Assessment of sexual matters with patients with acute MI is an important factor to prevent loss of sexual activity [23]. Lack of sexual education for patients with MI was a leading cause of absence or less frequent sexual activity in both male and female patients [23] [24]. Therefore, providing patients with sexual health information aids in improving patients' sexual interest and satisfaction through decreasing patients' and partner level of anxiety and fear from engaging in sexual activities and improve patients' sexual life [22]. Providing sexual health in- 
structions for patients with CADs is an essential nursing task [25]. Despite supporting evidence and increased attention to sexual health assessment over the years, it is still a challenge for many nurses to address sexual health in practice [13].

\subsection{Sexual Health Assessment in Clinical Practice}

Sexual health assessment in clinical practice is viewed as a private matter between partners by nurses and rarely discussed [26]. For example, in the United States, Lindau et al reported that only one-third of women and half of men with MI were educated about sexual health during their hospitalization [23]. In a phenomenological study, Andersson and colleagues [12] concluded that majority of young adults with MI mentioned that health care providers did not provide them with information about sexual health. Similar results were found by Ozdemir and Akdemir that none of 108 nurses in cardiac units provided sexual education to patients with CADs after recovery [27]. However, sexual health assessment is important to help patients resume their sexual life [28].

There is an increasing interest in providing holistic care that includes sexual health assessment [29]. Amongst other healthcare professionals, nurses can play a significant role in conducting sexual health assessment [30]. Nurses have good relationships with patients due to their daily contact with patients that facilitate assessment of sexual health [31]. Moreover, nurses documented that sexual health assessment for patients is a part of their professional role [32]. Nurses have shown little competence in sexual health assessment and therefore requires more practice by nurse clinicians [33]. In short, patients' sexual health assessment is a nursing task but nurses still hesitate to conduct sexual health assessment in clinical practice [4].

\section{Results}

Results were summarized from our review of to nursing, specifically and health related disciplines literature, generally regarding barriers that prevent nurses from conducting sexual health assessment. Barriers and strategies to integrate sexual health assessment in clinical practice are summarized in Table 1.

\subsection{Barriers for Assessment of Sexual Health}

Sexual health following CADs has gained a great attention in nursing research. Despite increase attention, sexual health assessment still is challenging for the vast majority of nurses. There are several authors that studied barriers to sexual health assessment in nursing practice in different cultural background [34]. For purposes of this paper, authors classified barriers based on previous research work and reviewing the literature into four main categories: nurses-related barriers, patients-related barriers, organizational related barriers and values-related barriers. Barriers to sexual health assessment is viewed differently by different cultures, authors studied barriers taking cultural backgrounds in consideration. This classification organizes and integrates all possible barriers in a comprehensive and clear way that might help nurse clinicians, educators, administrators and re- 
Table 1. Barriers and promoting activities for sexual health assessment in clinical practice.

\begin{tabular}{|c|c|c|c|}
\hline $\begin{array}{l}\text { Authors/Year } \\
\text { Country }\end{array}$ & Sample & Barriers & $\begin{array}{l}\text { Sexual health assessment } \\
\text { promotion activities }\end{array}$ \\
\hline $\begin{array}{c}\text { Kim, }(2010) \\
{[35]} \\
\text { Korean }\end{array}$ & $\begin{array}{c}310 \text { nurses } \\
\text { Descriptive study }\end{array}$ & $\begin{array}{l}\text { Nurses competencies in term } \\
\text { of knowledge, } \\
\text { communication skills and } \\
\text { training }\end{array}$ & $\begin{array}{l}\text { Development educational } \\
\text { program. } \\
\text { Patient-centered sexual } \\
\text { health curriculum. } \\
\text { Improves nurses' } \\
\text { communication skills }\end{array}$ \\
\hline $\begin{array}{l}\text { Jaarsma et al., } \\
(2010)[24] \\
\text { Sweden }\end{array}$ & $\begin{array}{l}157 \text { cardiac nurses } \\
\text { Descriptive survey }\end{array}$ & $\begin{array}{l}\text { Nurses beliefs that patients } \\
\text { may be upset, embarrassed or } \\
\text { anxious if they were asked } \\
\text { about sexual health } \\
\text { Insufficient knowledge to } \\
\text { answer patients' questions }\end{array}$ & $\begin{array}{l}\text { Providing nurses with } \\
\text { knowledge and practical } \\
\text { training increases their } \\
\text { comfort in discussion } \\
\text { patients' sexual health }\end{array}$ \\
\hline $\begin{array}{l}\text { Saunamaki et } \\
\text { al., (2010) [36] } \\
\text { Sweden }\end{array}$ & $\begin{array}{l}100 \text { nurses } \\
\text { Correlative } \\
\text { Comparative de- } \\
\text { sign }\end{array}$ & $\begin{array}{l}\text { Nurseslack confident and did } \\
\text { not make time to } \\
\text { address patients' sexual } \\
\text { concerns }\end{array}$ & $\begin{array}{l}\text { Education sessions to } \\
\text { improve nurses' positive } \\
\text { attitudes and confident in } \\
\text { addressing sexual health } \\
\text { concerns }\end{array}$ \\
\hline $\begin{array}{c}\text { Altiok and } \\
\text { Yilmaz, (2011) } \\
{[37]} \\
\text { Turkish }\end{array}$ & $\begin{array}{l}32 \text { patients with MI } \\
\text { descriptive and } \\
\text { qualitative design } \\
\text { Semi-structured } \\
\text { interviews }\end{array}$ & $\begin{array}{l}\text { Patients consider sex a pri- } \\
\text { vate issues that can be dis- } \\
\text { cussed with } \\
\text { others due to the } \\
\text { cultural perspectives of Tur- } \\
\text { kish society }\end{array}$ & $\begin{array}{l}\text { Provide appropriate } \\
\text { settings where patients can } \\
\text { express their sexual } \\
\text { problems comfortably } \\
\text { Consider sexual assessment } \\
\text { in patient care planning } \\
\text { and during patient } \\
\text { education. } \\
\text { Patients with MI have to } \\
\text { contact health care } \\
\text { providers and seek } \\
\text { for treatment. } \\
\text { Referral of patients to } \\
\text { experts and resource. } \\
\text { Establishing centers for } \\
\text { sexual counseling } \\
\text { Activate nurses' roles in } \\
\text { sexual counseling centers }\end{array}$ \\
\hline $\begin{array}{l}\text { Hoekstra et al., } \\
\quad(2012)[5] \\
\text { Netherlands }\end{array}$ & $\begin{array}{c}122 \text { Nurses } \\
\text { Descriptive survey }\end{array}$ & $\begin{array}{l}\text { Lack of organizational policy } \\
\text { Lack of training } \\
\text { Cultural, Religion, Language } \\
\text { and } \\
\text { Ethnicity issues } \\
\text { Age of the patient } \\
\text { The patient is too ill to ad- } \\
\text { dress sexual health } \\
\text { Sexuality is not } \\
\text { problem by the patient } \\
\text { Patients did not initiate sub- } \\
\text { ject Lack of } \\
\text { knowledge in general and } \\
\text { how to initiate the topic. } \\
\text { Nurses feel } \\
\text { uncomfortable }\end{array}$ & $\begin{array}{l}\text { Investigating barriers that } \\
\text { prevent nurses from } \\
\text { discussing sexual health } \\
\text { Select an appropriate time } \\
\text { and setting during follow } \\
\text { up visits or during review } \\
\text { of medications at cardiac } \\
\text { clinic }\end{array}$ \\
\hline
\end{tabular}




\section{Continued}

\begin{tabular}{|c|c|c|c|}
\hline $\begin{array}{l}\text { Thompson et al., } \\
\text { (2008) [38] } \\
\text { Northern } \\
\text { Ireland/UK }\end{array}$ & $\begin{array}{l}120 \text { GPs and } 52 \text { Nurses } \\
\text { Mixed methods design } \\
\text { Semi-structured } \\
\text { interviews }\end{array}$ & $\begin{array}{l}\text { Lack of awareness and } \\
\text { training. } \\
\text { Nurses feel } \\
\text { embarrassment Lack of } \\
\text { time }\end{array}$ & $\begin{array}{l}\text { Training programs for } \\
\text { health care providers on } \\
\text { handling sexual health }\end{array}$ \\
\hline $\begin{array}{c}\text { Akhu-Zaheya and } \\
\text { Masadeh, (2015) } \\
{[20]} \\
\text { Jordan }\end{array}$ & $\begin{array}{l}124 \text { patients with heart } \\
\text { diseases } \\
\text { Cross sectional } \\
\text { descriptive study }\end{array}$ & $\begin{array}{c}\text { Gender differences } \\
\text { between nurses and } \\
\text { patients due to cultural } \\
\text { perspectives }\end{array}$ & $\begin{array}{l}\text { Arrange for sexual } \\
\text { counseling plans with } \\
\text { patients. Developing and } \\
\text { integrating policies } \\
\text { regarding sexual health } \\
\text { assessment and education } \\
\text { before time of discharge }\end{array}$ \\
\hline $\begin{array}{c}\text { Ferreira et al., } \\
\text { (2015) [39] } \\
\text { Brazil }\end{array}$ & $\begin{array}{c}16 \text { different levels } \\
\text { nurses }\end{array}$ & $\begin{array}{l}\text { Nurses focus on } \\
\text { physical illness and } \\
\text { exclude sexual health } \\
\text { Institution culture } \\
\text { work (lack of time, } \\
\text { nurses' shortage and } \\
\text { turnover, workload, } \\
\text { and lack of private } \\
\text { areas). Sociocultural } \\
\text { perspective prohibit } \\
\text { talking about sexuality }\end{array}$ & $\begin{array}{l}\text { Multi-disciplinary tasks to } \\
\text { include sexual health in } \\
\text { clinical practice: Changes } \\
\text { the health care standard, } \\
\text { personal values and social } \\
\text { clarifications about sexual } \\
\text { health assessment }\end{array}$ \\
\hline
\end{tabular}

Integrate sexual

14 mental health

Quinn et al., (2011) [33] nurses A qualitative, exploratory approach

Australia (individual interviews)
Sexuality is not a priority Nurses stated: Sexual health assessment is not nursing task assessments as part of holistic care within nursing curriculum. Investigate

barriers to sexual assessment and develop appropriate measure to overcome

\begin{tabular}{|c|c|c|}
\hline $\begin{array}{l}\text { Purabuli, Azizzade } \\
\text { and Alizadeh, } \\
\text { (2010) }[40] \\
\text { Iran }\end{array}$ & $\begin{array}{c}300 \text { cardiac nurses } \\
\text { Analytical } \\
\text { cross-sectional study }\end{array}$ & $\begin{array}{c}\text { Inadequate Knowledge } \\
\text { Gender differences } \\
\text { between nurses and } \\
\text { patients }\end{array}$ \\
\hline
\end{tabular}

Promote nurses'

knowledge Providing sexual health assessment at time of discharge.

Providing sexual health assessment for patients who are same sex as nurses

Interventional educational program

_improves nurses'

This study aims to evaluate effectiveness

Sung and Lin, 190 nursing students

(2013) [41] A quasi-experimental

Taiwan, China design of sexual education on nursing students' knowledge, attitude, values, feelings and self-efficacy related to sexual healthcare knowledge; attitude and self-efficacy

-helps nursing students enhance their knowledge and explore their own values, feelings on patient sexuality

- prepares nursing students to address patients' sexual health and over-

come the possible barriers 


\section{Continued}

\begin{tabular}{|c|c|c|c|}
\hline $\begin{array}{l}\text { Huang, Tsai, } \\
\text { Tseng and Lee, } \\
\text { (2013) [42] } \\
\text { Taiwan, China }\end{array}$ & $\begin{array}{l}146 \text { senior nursing } \\
\text { students } \\
\text { Descriptive, } \\
\text { cross-sectional } \\
\text { study }\end{array}$ & $\begin{array}{l}\text { Nursing students' } \\
\text { attitudes towards } \\
\text { providing sexual } \\
\text { assessment }\end{array}$ & $\begin{array}{l}\text { Appropriate educational } \\
\text { programs improve } \\
\text { students' attitude } \\
\text { Studying nurses attitudes } \\
\text { gives a better } \\
\text { understanding regarding } \\
\text { barriers and facilitates } \\
\text { developing appropriate } \\
\text { interventions to improve } \\
\text { future nurses capabilities to } \\
\text { address sexual health in } \\
\text { clinical practice }\end{array}$ \\
\hline $\begin{array}{l}\text { Ivarsson, Fridlund, } \\
\text { and Sjöberg, } \\
\text { (2010) [43] } \\
\text { Sweden }\end{array}$ & $\begin{array}{l}\text { Nurses representing } \\
18 \text { coronary care } \\
\text { units } \\
\text { Explorative, qualit- } \\
\text { ative and content } \\
\text { analysis design }\end{array}$ & $\begin{array}{l}\text { Asking for sexual health } \\
\text { related } \\
\text { information following MI } \\
\text { is a patients' and their } \\
\text { partners' } \\
\text { responsibility } \\
\text { Insufficient written } \\
\text { information. Lack of } \\
\text { cooperation with sexual } \\
\text { health experts }\end{array}$ & $\begin{array}{l}\text { Well-educated and skillful } \\
\text { health care providers to } \\
\text { handle patients and } \\
\text { partners sexual health and } \\
\text { to provide them the } \\
\text { essential information. } \\
\text { Preparing written materials } \\
\text { about sexual health } \\
\text { information. Health } \\
\text { professionals have to } \\
\text { include sexual health } \\
\text { counselling as a part of } \\
\text { comprehensive care } \\
\text { approach }\end{array}$ \\
\hline $\begin{array}{c}\text { Byrne et al., (2013) } \\
\text { [19] } \\
\text { Scotland, UK }\end{array}$ & $\begin{array}{l}\text { 382Cardiac patients } \\
\text { and121 staff and } \\
\text { practitioners } \\
\text { Descriptive study }\end{array}$ & $\begin{array}{l}\text { For patient: lack of privacy } \\
\text { For health professionals: } \\
\text { Lack of time and of } \\
\text { training. Fear from patient } \\
\text { anxiety and discomfort if } \\
\text { they address their sexual } \\
\text { issues }\end{array}$ & $\begin{array}{l}\text { Developing interventions } \\
\text { to improve healthcare } \\
\text { providers' competencies. } \\
\text { Providing patients with } \\
\text { information materials } \\
\text { about sexual health }\end{array}$ \\
\hline $\begin{array}{l}\text { Goossens et al., } \\
\text { (2011) [31] } \\
\text { Denmark, } \\
\text { Norway, Belgium, } \\
\text { Flanders and } \\
\text { Wallonia }\end{array}$ & $\begin{array}{l}819 \text { European } \\
\text { cardiovascular } \\
\text { nurses } \\
\text { cross-sectional } \\
\text { descriptive study }\end{array}$ & $\begin{array}{l}\text { Culture affects nurses' } \\
\text { level of practice, } \\
\text { responsibility and } \\
\text { confidence and affects } \\
\text { patients' level of } \\
\text { comfort toward sexual } \\
\text { health assessment }\end{array}$ & $\begin{array}{l}\text { Establishing nursing } \\
\text { interventions to promote } \\
\text { sexual health discussion for } \\
\text { patients with heart } \\
\text { diseases. Educational } \\
\text { courses and training for } \\
\text { healthcare providers } \\
\text { regarding sexual health that } \\
\text { is sociocultural sensitive } \\
\text { and appropriate to be able } \\
\text { to deal with different } \\
\text { cultural backgrounds }\end{array}$ \\
\hline $\begin{array}{l}\text { Ivarsson, Fridlund, } \\
\text { and Sjöberg, } \\
\text { (2009) [44] } \\
\text { Sweden }\end{array}$ & $\begin{array}{l}\text { Cardiac health care } \\
\text { providers in } 121 \\
\text { coronary care units } \\
\text { for patients with MI } \\
\text { National survey }\end{array}$ & $\begin{array}{l}\text { Cardiac health care teams } \\
\text { rarely provide oral or } \\
\text { written } \\
\text { information regarding } \\
\text { sexual health for } \\
\text { patients and partners. } \\
\text { Cardiac health care pro- } \\
\text { viders lack sexual health } \\
\text { competences }\end{array}$ & $\begin{array}{l}\text { Encourage health care } \\
\text { providers to educate } \\
\text { patients with MI about } \\
\text { sexual health. } \\
\text { Provide patients and } \\
\text { partners with written } \\
\text { information about sexual } \\
\text { health. Conducting more } \\
\text { research regarding } \\
\text { patients' and their partners' } \\
\text { need for sexual health } \\
\text { related information }\end{array}$ \\
\hline
\end{tabular}




\begin{tabular}{|c|c|c|c|}
\hline $\begin{array}{c}\text { Magnan and } \\
\text { Reynolds, (2006) } \\
{[45]} \\
\text { United States }\end{array}$ & $\begin{array}{l}302 \text { nurses } \\
\text { A descriptive } \\
\text { correlational } \\
\text { design }\end{array}$ & $\begin{array}{l}\text { Nurses' perception that } \\
\text { patients do not expect } \\
\text { nurses to address } \\
\text { sexual health. } \\
\text { Lack of comfort and } \\
\text { confidence Nurses' } \\
\text { inability to make time for } \\
\text { sexual health } \\
\text { discussion }\end{array}$ & $\begin{array}{l}\text { Educational programs about } \\
\text { sexual health to overcome per- } \\
\text { ceived barriers Using } \\
\text { nursing competencies to } \\
\text { develop creative methods to } \\
\text { overcome barriers to } \\
\text { addressing patient sexual health } \\
\text { Conducting more } \\
\text { research to study patients' ex- } \\
\text { pectations }\end{array}$ \\
\hline $\begin{array}{l}\text { O’Donovan, } \\
(2012)[46] \\
\text { Irland }\end{array}$ & $\begin{array}{l}\text { Both patients } \\
\text { with } \\
\text { MI and } \\
\text { nurses }\end{array}$ & $\begin{array}{l}\text { Nurses embarrassment } \\
\text { Nurses Uncomfortable } \\
\text { with his or her own sexual- } \\
\text { ity. Nurses' feeling that } \\
\text { discussion sexual health is } \\
\text { an invasion of the patient's } \\
\text { privacy. Nurses are busy } \\
\text { due to workload Lack } \\
\text { suitable place to conduct } \\
\text { sexual health assessment } \\
\text { Nurses consider } \\
\text { patients with MI are too ill }\end{array}$ & $\begin{array}{l}\text { Conducting workshops about } \\
\text { sexual health } \\
\text { Encourage discussion of sexual } \\
\text { health through using of open } \\
\text { questions } \\
\text { Providing patient with } \\
\text { educational materials }\end{array}$ \\
\hline $\begin{array}{c}\text { Saunamäki and } \\
\text { Engström, (2014) } \\
\text { [30] } \\
\text { Sweden }\end{array}$ & $\begin{array}{l}10 \text { nurses A } \\
\text { descriptive } \\
\text { design and } \\
\text { qualitative } \\
\text { content } \\
\text { analysis }\end{array}$ & $\begin{array}{l}\text { Nurses feel embarrassment, } \\
\text { fear and sexual health } \\
\text { assessment is not their } \\
\text { responsibility Lack of time, } \\
\text { support and privacy Sexual } \\
\text { related topics are taboo }\end{array}$ & $\begin{array}{l}\text { Inspire nurses to understand } \\
\text { how they can addressing } \\
\text { patients' sexual health. Health } \\
\text { care institutions have to } \\
\text { encourage nurses and provide } \\
\text { them with access to address } \\
\text { sexual health. Increase nurses' } \\
\text { knowledge and comfort }\end{array}$ \\
\hline
\end{tabular}

searchers where to focus to find the most appropriate interventions to facilitate sexual health assessment.

\subsection{Nurses-Related Barriers}

In order to find out the main barriers that constrain nurses from addressing patients' sexual health in clinical practice, Ho and Fernández found that lack of education, embarrassment, cultural restrictions, lack of experience and religious prohibitions are the main barriers [47]. Saunamäki and Engström reported that some nurses thought that sexual health assessment is a taboo subject and therefore it should not be discussed and it is not within their job description and it is someone else's responsibility [30]. Doherty et al. mentioned lack of proper training on how to discuss sexual health issues as a barrier [34].

Other barriers include insufficient nurses' knowledge and viewing sexual health as a private matter between adult partners that should not be discussed by nurses [27], lack of time to prepare and feeling uncomfortable to provide patients with sexual education [24]. Some nurses view assessment of patients' sexual health as at low priority [33] or make them upset, embarrassed or anxious [24]. Byrne and colleagues found that lack of enough time due to workload, feeling 
that patients are not ready to receive sexual information and lack of education and training are important barriers that nurses may encounter [48].

Magnan and Reynolds [45] investigated the main barriers for sexual health assessment in five fields of specialization $(\mathrm{N}=302)$ and found that nurses perceived that sexual health is not a part of their patient care have coalesced with their lack of comfort, confidence and time to discuss patient sexual health needs. Huang et al. found that nurses are uncomfortable when addressing patients' sexual health matters [42]. Doherty et al. outlined a list of barriers including patients' lack of readiness, knowledge deficit and lack of training programs for nurses [34]. Saunamäki, Andersson and Engström found that Sweden nurses are knowledgeable in sexual health field, feel comfortable and responsible and show readiness to do sexual health assessment, but the vast majority of them did not address patients' sexual health as they feel unconfident and did not specify a time to do so [36].

Finally, nurses' beliefs and attitudes toward sexual health may prevent them from assessing patients' sexual health. Most of nurses who never assess patients' sexual health have a negative attitude toward sexual health discussion [48]. The main responses that affect health care providers' attitudes are difficulties in answering to patients' sexual problems, concerns, and questions and lack of confidence, skills and training [49]. Some nurses have personal beliefs and values that assessment of sexual issues is not ethical [50]. Therefore, understanding nurses' attitudes towards addressing patients' sexual health is an important consideration by encouraging nurses to attend to patients' sexual concerns within the routine nursing care.

\subsection{Patient-Related Barriers}

Additional barriers were found that were not related to the competency of health care providers. Patient related factors can also impede the addressing of sexual health needs. Many patients reported their interest to discuss sexual concerns with health care providers, but they did not do so because they are embarrassed [51], or believe that they just have experienced a diminishing sexuality due to normal ageing process [52]. Sometimes, nurses may be reluctant to start sexual assessment and teaching because they fear that discussion of sexual related issues can annoy the patient [51] or fear from any unexpected response from patients [53]. Buttaro et al reported that pateints' age, culture, sexual orientation, comorbidity diseases, and limited time are main barriers to sexual health assessment [54].

\subsection{Organizational-Related Barriers}

Some barriers are related to the academic and health care institutions. Doherty and colleges stated that cardiac nurses ignore sexual health assessment because health institutions lack guidelines regarding sexual assessment and management, specialized referral clinics and nurses do not have enough confidence, knowledge and training [34]. Hoekstra et al. [5] reported that lack of health policies about addressing sexual health was the main barrier. Furthermore, Quinn and colleagues found that healthcare organization view sexual health assessment is 
not a priority [33]. In China, nurses reported that nurses' shortage and lack of resources are significant barriers to address patients' sexual health [55]. Furthermore, lack of support from the institutions [56], lack of privacy [57], work overload and a sense that addressing sexual health is non-nursing job [29] are cited as organizational barriers.

Academic nursing curricula in Jordan often ignore discussing of sexual health issues for nursing students. Despite that, several studies reported that addressing sexual health issues during undergraduate education is vital to increase nurses' knowledge [33] [58].

\subsection{Values-Related Barriers}

Finally, culture, society, and religion are external barriers that are related to values of persons or community preventing assessment of sexual health with patients during their hospitalization. Many cultures including Arab Islamic culture considering sexual related topics are sensitive. Goossens et al examined the impact of culture in five Europe countries and found that nurses' beliefs and attitudes about sexual health are influenced by both culture and country [30]. In some cultures, there is a common belief that sexual health is not a matter for older adults or those who with chronic conditions [59]. Turkish nursing students' did not offer sexual health assessment and education to patients due to effects of cultural and religious beliefs [60]. In the Turkish culture, open communications about sexual matters between different sexes is prohibited, then preventing nurses from sexual health assessment [61].

Societal restrictions can interfere with providing sexual health care [29]. $\mathrm{Pu}$ rabuli, Azizzade and Alizadeh found that most nurses in Iran (96\%) highlight the necessity for nurse educators to be same sex as the patient [40]. Social interpretation of sexual issues is another barrier, for example, sex means pleasure and enjoyment and it is not logical to address it during illness. Based on this interpretation, Chinese nurses pay more attention to physical health condition rather than sexual concerns [55].

In summary, to gain more depth insight, all possible barriers to sexual health assessment in nursing practice based on reviewed studies are outlined below in Table 2.

\subsection{Promoting Strategies for Sexual Health Assessment in Nursing Practice}

As sexual health-related needs are sensitive issues and often challenging task for nurses. Special considerations are required to help nurses conducting patients' sexual health assessment in clinical practice. In attempts to overcome barriers, we suggest a multidisplinary team to develop standardized guidelines to sexual health assessment. Strategies to facilitate sexual health assessment are outlined below.

First: Integrate sexual health assessment topics in nursing curriculum during undergraduate studies. Jaarsma et al. found that nurses have knowledge deficit 
Table 2. Barriers to sexual health assessment in clinical nursing practice.

\begin{tabular}{|c|c|}
\hline Category & Barriers \\
\hline Nurses related barriers & $\begin{array}{l}\text { Lack enough time to address patients' sexual health } \\
\text { Lack of knowledge about sexual health } \\
\text { Lack of training about sexual health } \\
\text { Nursing shortage and heavy workload* } \\
\text { Lack of educational materials about sexual health }{ }^{*} \\
\text { Sexual health assessment is not nurses' responsibility } \\
\text { (physician)* } \\
\text { The patient is too ill and not ready for sexual health } \\
\text { assessment } \\
\text { Nurses feel uncomfortable with sexual health assessment } \\
\text { Presence of a third party with patient during hospital stay } \\
\text { Afraid to offend the patient or afraid from offend response } \\
\text { No connection with the patient } \\
\text { Gender difference (male-female) between nurses and } \\
\text { patients* } \\
\text { Focus on physical illness rather than sexual health } \\
\text { Sex is a private matter } \\
\text { Patients do not ask about sexual health } \\
\text { Misunderstanding of nurse who ask about sexual health } \\
\text { maters (Social interpretation)* } \\
\text { Nurses own beliefs, values and attitudes about sexual health }\end{array}$ \\
\hline Patient related barriers & $\begin{array}{l}\text { Sexuality is not an issue for some patients (not interested) } \\
\text { The patient is too ill and not ready to receive sexual health } \\
\text { assessment } \\
\text { Presence of a third party with patient during hospital stay } \\
\text { Patients do not ask about sexual health } \\
\text { Old age of the patient } \\
\text { Sexual health assessment is not nurses' responsibility } \\
\text { (physician)* } \\
\text { Gender difference (male-female) between nurses and } \\
\text { patients } \\
\text { Misunderstanding of patient who ask about sexual health } \\
\text { maters (Social interpretation) }\end{array}$ \\
\hline $\begin{array}{l}\text { Organizational and academic } \\
\text { related barriers }\end{array}$ & $\begin{array}{l}\text { Lack of privacy rooms for sexual health assessment } \\
\text { Lack of educational materials about sexual health } \\
\text { Lack of motivation from health care institutions (low } \\
\text { priority) } \\
\text { Lack of sexual health assessment section from nursing } \\
\text { assessment sheet } \\
\text { Lack of organizational policies about sexual health } \\
\text { assessment } \\
\text { Nursing shortage and heavy workload } \\
\text { Lack sexual health education in undergraduate studies }\end{array}$ \\
\hline Value related barriers & $\begin{array}{l}\text { Cultural or religious reasons } \\
\text { Social restrains prevent talks about sexual topics } \\
\text { Language or ethnicity reasons } \\
\text { Sex is a private matter } \\
\text { Age difference between nurse and patient (old patient and } \\
\text { young nurse) } \\
\text { Gender difference (male-female) between nurses and } \\
\text { patients } \\
\text { Social interpretation of sex (means pleasure and } \\
\text { enjoyment) } \\
\text { Nurses own beliefs, values and attitudes about sexual } \\
\text { health }\end{array}$ \\
\hline
\end{tabular}

${ }^{\star}$ Means that barrier is related to two or more categories. 
and lack of confidence to talk about sexual matters [24]. Well-prepared nurses in term of knowledge and skills make them more confident in providing sexual health assessment and information.

Second: Conduct training sessions and workshops on sexual health assessment for nurses in clinical setting (sexual health competency). Training programs about sexual health improve nurses' comfort and attitude toward bringing sexual health assessment into practice [35] [36]. Clinical training workshops with simulation role-play case scenarios by nurse specialist in sexuality matters is highly recommended to help nurses addressing patients' sexual health [24].

Third: Teach effective communication skills to nurses and build rapport and therapeutic relationship between nurse and patients to make nurses more able to translate their acquired sexual knowledge into practice [55]. The close relationship between nurses and patients gives both a great chance to discuss sexual concerns [62]. Nurses could use their art to address patients' sexual health in a way that fit with patients' values, beliefs, culture and religion. As many cultures view sexual matters as secret and private, nurses need to take cultural perceptions in the process of sexual health assessment [37]. To achieve a successful addressing of sensitive information, Waltz, Strickland and Lenz recommended ensuring privacy and confidentiality of patients' responses; seeking only relevant data starting from less to more sensitive and allowing more time for participants to express their needs [63].

Fourth: Use written educational material such as brochures and leaflets that are developed by experts about sexual health. These materials play an important role in improving patients' knowledge and encourage patients to express their sexual health concerns [19].

Fifth: Select appropriate time is an important factor for effective assessment and teaching of patients' sexual health. For example, nurses viewed that time is not suitable for discussing sexual concerns as patients are ill and they may have anxiety and fear due to their conditions [59]. As existence of third party is a barrier, before or after visiting hours is more appropriate for both nurse and patient to address sexual health needs. Discharge period is a suitable time where patients become stable and ready for assessment and to receive information. Three quarters of nurses recommended that the best time to assess patients' sexual health is during their follow-up visits or during medications review [5].

Sixth: Create, adopt and implement sexual health policies and procedures for sexual health assessment in clinical settings to facilitate nurses' roles in conducting this important nursing task [34]. For example, integrating sexual assessment as a part to the nurses' charts enable nurses to address the sexual health during history taking and discharge planing. Annon developed the PLISSIT model as a tool to facilitate the assessment and treatment of sexual related problems. PLISSIT letters are abbreviations for sequent interventions where P means Permission; LI means Limited Information; SS mean Specific Suggestions and IT means Intensive Therapy [64]. The PLISSIT model is a framework that helps nurses to conduct sexual health assessment [42]. 
Seventh: Invite partners during sexual health assessment and counseling. Partners may complain of distress and anxiety that may affect patient's sexual health [65]. Partners play significant roles in patient support and facilitating successful resuming of sexual activities.

Eighth: Break down external barriers, Media can play a vital role in discussing the sexual health and related concerns publicly. Nurses can present a television shows about sexual health and instructions for patients and their partners.

Ninth: Nurses need to understand patients and partners' sexual health experiences and needs for sexual health information, nurses' knowledge, attitudes, beliefs, barriers and best teaching methods. Conducting more research in sexual health nursing field is recommended to improve sexual health assessment [44].

Tenth: Create an appropriate work environment through establishing specialized rooms in health institutions to help both nurses and patients to address sexual health related issues in a more comfortable manner [37].

\section{Discussion}

To our knowledge, this is the first nursing review of literature to explore the all-possible barriers and promoting strategies from different cultures on sexual health assessment in clinical nursing practice. It is well documented that CADs have a negative impact on sexual health, both physically and psychologically [43] [66]. Therefore, patients actually need assessment and guidance regarding their sexual concerns after recovery. Several authors reported adequately that assessment of sexual matters is an important factor to prevent loss of sexual activity [23]. Providing patients with sexual health information shows a significant improvement in patients' sexual interest and satisfaction through decreasing patients' and partner level of anxiety and fear from engaging in sexual activities and improve patients' sexual life [22]. It is clear enough that sexual health assessment is an important nursing task [25].

Based on WHO definition of sexual health, we recognized that sexual health is interrelated with other health domains and therefore nurses need to recognize the importance of addressing sexual health as a part of routine nursing care. However, the findings of reviewed studies indicated that sexual health assessment is often neglected in clinical practice. For example, according to Jaarsma and colleagues; results showed that only $10 \%$ of nurses address patients' sexual health concerns [24]. In Jordan, the same percentage of patients with heart diseases did receive sexual health related assessment and instructions [20].

Studies have shown that there are multifactorial barriers that prevent nurses from conducting patients' sexual health assessment during their hospitalizations stay or during follow up visits. These barriers are categorized as patient related barriers, nurses related barriers, organizational related barriers and value related barriers.

First category of barriers are related to nurses, actually nurses may ignore patients sexual health assessment because they do not have an adequate knowledge, training, time, facilities, confidence and comfort. For example, studies have shown 
that nurses are not prepared to handle patients' sexual health [34]. In particular, nurses' attitude and beliefs might influence their behaviors to conduct sexual health assessment. Some nurses consider sex is a taboo subject and it is not their responsibility [30]. A thorough understanding of nurse related barriers including their attitudes and beliefs can provide essential information to establish appropriate interventions that improve sexual health care. Nurses' age, experience, adequate knowledge and training are factors that contribute to confident and comfort in their ability to address patients' sexual health [36] and as a result, they are more able to make a time to address the patients' sexual health [59]. Based on these results, it seems clearly that providing nurses with sexual education and training is beneficial to overcome barriers to sexual health assessment.

The second category of barriers is relevant to patients. Patients may feel embarrassed, not interested in discussion of their sexual concerns, and may have an offend responses against initiations of their sexual health assessment. Therefore, explaining patients' needs and concerns to find practical and appropriate strategies to handle their sexual health is an essential in their recovery. Patients with CADs reported the importance of addressing sexual health and showed interest in receiving sexual health instructions [52] [67]. As patients are not ready to receive sexual health information during their illness, Purabuli et al recommended providing sexual health assessment at the time of discharge [40]. In addition, following appropriate procedures that are culturally sensitive may encourage patients to vent their needs for sexual health information.

The third category that prevents nurses to consider patients' sexual health assessment is related to health care organizations. For example, work environment also has barriers to sexual health assessment including lack of time, heavy workload, unavailability of educational materials, and lack of sexual health assessment section in nursing health assessment sheet, privacy issues such as no specialized rooms and the existence of third party with patients during their hospital stay. Academic and clinical health institutions need to prepare and support nurses to initiate assessment of sexual health by providing them with required knowledge and practical training, develop and adopt sexual health protocols, establish policies that consider sexual assessment within patients' plan of care and providing comfort and private rooms. Despite the importance of adopting evidence guidelines and recommendation about sexual health in clinical setting, Hoekstra and colleagues [5] found that policies regarding discussing patients' sexual health are still lacking. In summary, health institution plays a role in creating a comfortable work environment for nurses to assess patient's sexual needs [68].

The last category of barriers is surrounding external factors such as value related barriers that make both patients and nurses hesitated to initiate sexual health assessment. Certain cultures such as Scandinavian consider talking about sexual matters is liberating; for example, Swedish critical care nurse do not view culture as a barrier to provide sexual health assessment [43]. In opposite, many eastern cultures including Arabic culture has more restrictions over sexual matters. Due to the complexity and sensitivity of the topic, nurses have to consider 
cultural and social perspectives of patients during sexual health assessment. Nurses are a part of the culture where they live; both nurses and patients may feel uncomfortable to talk about sexual issues in the hospital environment.

While nurses avoidance of sexual health assessment in nursing settings were mentioned clearly in the previous studies, it is obvious that there is a need for more studies that examine the actual barriers and to search for practical interventions that encourage nurses to address patients' sexual health routinely. This study might help nurse administrators, educators, and policy makers to gain more in depth understanding of barriers and promoting interventions toward sexual health assessment that ultimately could improve patients' sexual health and quality of nursing care. Furthermore, this study may bring attention and awareness that encourage nurses to include assessment of sexual health as a part of patient holistic care. On other hand, this study might contribute to the body of knowledge; support studies related to sexual health in nursing and other health professions and open the door to further interventional studies.

Limitations: Few studies used qualitative approach, which limits the understanding of phenomenology of sexual health assessment and the real barriers. Most studies are descriptive.

Implications and Recommendations: An action plan to overcome barriers is required from all parties. Overall, the findings illustrate a range of strategies that are important regarding improvement of patients' sexual health assessment, for example, improving nurses' proficiency in sexual health assessment, developing appropriate and culturally acceptable teaching methods, adopting and implementing scientific guidelines, and integrating the sexual assessment section to nursing papers. Nursing administrators have a pivotal role in creating a good environment for assessing patients' sexual health. Lange and Levine have been recommended to establish cardiac rehabilitation program for sexual health assessment and counseling [69]. Nurse researchers are in a key position to investigate patients and nurses points of view regarding sexual health assessment in term of knowledge, needs, attitudes, beliefs, and barriers by conducting more qualitative studies to gain better understanding. Then, appropriate ways of sexual health assessment can be developed and implemented. Providing sexual health assessment helps to improve patients' quality of life and nurses' quality of care. This study may corporate advancement of nursing knowledge and help nurses to conduct sexual health assessment routinely.

\section{Conclusions}

This review examined the current state of knowledge regarding barriers and promoting strategies to sexual health assessment in clinical nursing practice.

Results of this review revealed that sexual health was seldom examined and assessed in nursing profession domains of practice, research and education and nurses did not pay enough attention to patient's sexual health. We concluded that it was important to provide sexual health assessment in clinical practice as a part of holistic nursing care. However, to improve sexual health assessment, nurses 
and researchers need to investigate the real barriers and design appropriate interventions to increase nurses and patients awareness towards sexual health. Sexual health assessment needs to be standardized in most of health care institutions [70].

Several studies have shown that there is an urgent need for nurses to be welleducated and skillful in addressing patients' sexual issues following CADs [43]. As nurses are in direct contact with patients, nurses have a key role to assess and provide patients with CADs with appropriate instructions [41]. In summary, providing patients with sexual health information is an essential aspect of patient discharge plan [46].

\section{References}

[1] WHO (2006) Defining Sexual Health-Report of a Technical Consultation on Sexual Health 28-31 January 2002, Geneva. Sexual Health Document Series, World Health Organization, Geneva.

[2] Lindau, S.T., Schumm, L.P., Laumann, E.O., Levinson, W., O’Muircheartaigh, C.A. and Waite, L.J. (2007) A Study of Sexuality and Health among Older Adults in the United States. New England Journal of Medicine, 357, 762-774.

https://doi.org/10.1056/NEJMoa067423

[3] Stein, R., Sardinha, A. and Araújo, C.G. (2016) Sexual Activity and Heart Patients: A Contemporary Perspective. Canadian Journal of Cardiology, 32, 410-420. https://doi.org/10.1016/j.cjca.2015.10.010

[4] Hardin, S.R. (2007) Cardiac Disease and Sexuality: Implications for Research and Practice. Nursing Clinics of North America, 42, 593-603. https://doi.org/10.1016/j.cnur.2007.07.006

[5] Hoekstra, T., Lesman-Leegte, I., Couperus, M.F., Sanderman, R. and Jaarsma, T. (2012) Care of the Patient with Heart Failure: What Keeps Nurses from the Sexual Counseling of Patients with Heart Failure? Heart \& Lung-The Journal of Acute and Critical Care, 41, 492-499. https://doi.org/10.1016/j.hrtlng.2012.04.009

[6] World Health Organization (2015) Cardiovascular Diseases (CVDs). http://www.who.int/mediacentre/factsheets/fs317/en/

[7] Go, A.S., Mozaffarian, D., Roger, V.L., Benjamin, E.J., Berry, J.D., Blaha, M.J. and Fullerton, H.J. (2014) Heart Disease and Stroke Statistics-2014 Update. Circulation, 129, e28-e292.

[8] Jordanian Ministry of Health (2011) Mortality Data. Jordanian Ministry of Health Publications, Amman.

[9] Steinke, E.E., Hill, T.J. and Mosack, V. (2016) Medication Use and Predictors of Sexual Activity in Men and Women with CVD. Journal of the American Association of Nurse Practitioners, 28, 91-97. https://doi.org/10.1002/2327-6924.12253

[10] Jaarsma, T. (2007) Addressing Sexual Activity in Education of Heart Failure Patients. International Journal of Clinical Practice, 61, 353-355. https://doi.org/10.1111/j.1742-1241.2006.01270.x

[11] Winter, M.M., Reisma, C., Kedde, H., Bouma, B.J., Vis, J.C., Luijendijk, P. and van Dijk, A.P. (2010) Sexuality in Adult Patients with Congenital Heart Disease and Their Partners. The American Journal of Cardiology, 106, 1163-1168. https://doi.org/10.1016/j.amjcard.2010.06.027

[12] Andersson, E.K., Borglin, G. and Willman, A. (2013) The Experience of Younger 
Adults Following Myocardial Infarction. Qualitative Health Research, 23, 762-772. https://doi.org/10.1177/1049732313482049

[13] Miner, M. and Kim, E.D. (2015) Mine Cardiovascular Disease and Male Sexual Dysfunction. Asian Journal of Andrology, 17, 3-4.

https://doi.org/10.4103/1008-682X.143753

[14] Miner, M., Esposito, K., Guay, A., Montorsi, P. and Goldstein, I. (2012) Cardiometabolic Risk and Female Sexual Health: The Princeton III Summary (CME). The Journal of Sexual Medicine, 9, 641-651. https://doi.org/10.1111/j.1743-6109.2012.02649.x

[15] Jaarsma, T., Fridlund, B. and Mårtensson, J. (2014) Sexual Dysfunction in Heart Failure Patients. Current Heart Failure Reports, 11, 330-336.

https://doi.org/10.1007/s11897-014-0202-z

[16] Dalteg, T., Benzein, E., Fridlund, B. and Malm, D. (2011) Cardiac Disease and Its Consequences on the Partner Relationship: A Systematic Review. European Journal of Cardiovascular Nursing, 10, 140-149. https://doi.org/10.1016/j.ejcnurse.2011.01.006

[17] Schumann, J., Zellweger, M.J., Di Valentino, M., Piazzalonga, S. and Hoffmann, A. (2010) Sexual Dysfunction before and after Cardiac Rehabilitation. Rehabilitation Research \& Practice, 2010, Article ID: 823060. https://doi.org/10.1155/2010/823060

[18] Mulat, B., Arbel, Y., Mashav, N., Saar, N., Steinvil, A., Heruti, R. and Justo, D. (2010) Male Sexual Dysfunction: Depressive Symptoms and Erectile Dysfunction in Men with Coronary Artery Disease. Urology, 75, 104-107. https://doi.org/10.1016/j.urology.2009.09.041

[19] Byrne, M., Doherty, S., Murphy, A.W., McGee, H.M. and Jaarsma, T. (2013) The Charms Study: Cardiac Patients' Experiences of Sexual Problems Following Cardiac Rehabilitation. European Journal of Cardiovascular Nursing, 12, 558-566. https://doi.org/10.1177/1474515113477273

[20] Akhu-Zaheya, L.M. and Masadeh, A.M. (2015) Sexual Information Needs of ArabMuslim Patients with Cardiac Problems. European Journal of Cardiovascular Nursing, 14, 478-485. https://doi.org/10.1177/1474515115597353

[21] Levine, G.N., Steinke, E.E., Bakaeen, F.G., Bozkurt, B., Cheitlin, M.D., Conti, J.B. and Stewart, W.J. (2012) Sexual Activity and Cardiovascular Disease a Scientific Statement from the American Heart Association. Circulation, 125, 1058-1072. https://doi.org/10.1161/CIR.0b013e3182447787

[22] Byrne, M., Doherty, S., Fridlund, B.G., Mårtensson, J., Steinke, E.E., Jaarsma, T. and Devane, D. (2014) Sexual Counseling for Sexual Problems in Patients with Cardiovascular Disease. The Cochrane Library, No. 2, 1-12.

[23] Lindau, S.T., Abramsohn, E., Gosch, K., Wroblewski, K., Spatz, E.S., Chan, P.S. and Krumholz, H.M. (2012) Patterns and Loss of Sexual Activity in the Year Following Hospitalization for Acute Myocardial Infarction (a United States National Multisite Observational Study). The American Journal of Cardiology, 109, 1439-1444. https://doi.org/10.1016/j.amjcard.2012.01.355

[24] Jaarsma, T.S., De Geest, S., Mårtensson, J., Moons, P., Smithh, K. and Thompson, D. (2010) Sexual Counselling of Cardiac Patients: Nurses' Perception of Practice, Responsibility and Confidence. European Journal of Cardiovascular Nursing, 9, 2429. https://doi.org/10.1016/j.ejcnurse.2009.11.003

[25] Nicolai, M., Both, S., Liem, S., Pelger, R., Putter, H., Schalij, M. and Elzevier, H. (2013) Discussing Sexual Function in the Cardiology Practice. Clinical Research in Cardiology, 102, 329-336. https://doi.org/10.1007/s00392-013-0549-2

[26] Bispo, G.S., Lima Lopes, J. and Barros, A.L. (2013) Cardiovascular Changes Result- 
ing from Sexual Activity and Sexual Dysfunction after Myocardial Infarction: Integrative Review. Journal of Clinical Nursing, 22, 3522-3531. https://doi.org/10.1111/jocn.12356

[27] Özdemir, L. and Akdemir, N. (2008) Nurses' Knowledge and Practice Involving Patients' Resuming Sexual Activity Following Myocardial Infarction: Implications for Training. Australian Journal of Advanced Nursing, 26, 42-52.

[28] Reesea, J.P., Shelbyb, R.A. and Taylorc, K.L. (2012) Sexual Quality of Life in Patients Undergoing Coronary Artery Bypass Graft Surgery. Psychology and Health, 27, 721-736.

[29] Kotronoulas, G., Papadopoulou, C. and Patiraki, E. (2009) Nurses' Knowledge, Attitudes and Practices Regarding Provision of Sexual Health Care in Patients with Cancer: Critical Review of the Evidence. Supportive Care in Cancer, 17, 479-501. https://doi.org/10.1007/s00520-008-0563-5

[30] Saunamäki, N. and Engström, M. (2014) Registered Nurses' Reflections on Discussing Sexuality with Patients: Responsibilities, Doubts and Fears. Journal of Clinical Nursing, 23, 531-540. https://doi.org/10.1111/jocn.12155

[31] Goossens, E., Norekvål, T.M., Faerch, J., Hody, L., Olsen, S.S., Darmer, M.R. and Moons, P. (2011) Sexual Counselling of Cardiac Patients in Europe: Culture Matters. International Journal of Clinical Practice, 65, 1092-1099. https://doi.org/10.1111/j.1742-1241.2011.02756.x

[32] Vitrano, V., Catania, V. and Mercadante, S. (2011) Sexuality in Patients with Advanced Cancer: A Prospective Study in a Population Admitted to an Acute Pain Relief and Palliative Care Unit. American Journal of Hospice \& Palliative Medicine, 28, 198-202. https://doi.org/10.1177/1049909110386044

[33] Quinn, C., Happell, B. and Browne, G. (2011) Talking or Avoiding? Mental Health Nurses' Views about Discussing Sexual Health with Consumers. International Journal of Mental Health Nursing, 20, 21-28. https://doi.org/10.1111/j.1447-0349.2010.00705.x

[34] Doherty, S., Byrne, M., Murphy, A. and McGee, H. (2011) Cardiac Rehabilitation Staff Views about Discussing Sexual Issues with Coronary Heart Disease Patients: A National Survey in Ireland. European Journal of Cardiovascular Nursing, 10, 101 107. https://doi.org/10.1016/j.ejcnurse.2010.05.002

[35] Kim, J. (2010) Factors Influencing Barriers to Addressing Patients' Sexual Health among Clinical Nurse. Journal of Korean Academy of Adult Nursing, 22, 113-120.

[36] Saunamäki, N., Andersson, M. and Engström, M. (2010) Discussing Sexuality with Patients: Nurses' Attitudes and Beliefs. Journal of Advanced Nursing, 66, 1308 1316. https://doi.org/10.1111/j.1365-2648.2010.05260.x

[37] Altıok, M. and Yilmaz, M. (2011) Opinions of Individuals Who Have Had Myocardial Infarction about Sex. Sexuality and Disability, 29, 263-273. https://doi.org/10.1007/s11195-011-9217-5

[38] Thompson, K., Casson, K., Fleming, P., Dobbs, F., Parahoo, K. and Armstrong, J. (2008) Sexual Health Promotion in Primary Care-Activities and Views of General Practitioners and Practice Nurses. Primary Health Care Research \& Development, 9, 319-330. https://doi.org/10.1017/S1463423608000881

[39] Ferreira, S.M., Gozzo, T.D., Panobianco, M.S., Santos, M.A. and Almeida, A.M. (2015) Barriers for the Inclusion of Sexuality in Nursing Care for Women with Gynecological and Breast Cancer: Perspective of Professionals. Revista latino-americana de enfermagem, 23, 82-89. https://doi.org/10.1590/0104-1169.3602.2528

[40] Purabuli, B., Azizzade Foruzi, M. and Mohammad Alizadeh, S. (2010) Knowledge and Attitude of Nurses towards Sexual Activity and Training Patients with Myocar- 
dial Infarction and Their Spouses. Iranian Journal of Critical Care Nursing, 2, 145148.

[41] Sung, S.C. and Lin, Y.C. (2013) Effectiveness of the Sexual Healthcare Education in Nursing Students' Knowledge, Attitude and Self-Efficacy on Sexual Healthcare. Nurse Education Today, 33, 498-503. https://doi.org/10.1016/j.nedt.2012.06.019

[42] Huang, C., Tsai, L., Tseng, T., Li, C. and Lee, S. (2013) Nursing Students' Attitudes towards Provision of Sexual Health Care in Clinical Practice. Journal of Clinical Nursing, 22, 3577-3586. https://doi.org/10.1111/jocn.12204

[43] Ivarsson, B., Fridlund, B. and SjÃberg, T. (2010) Health Professionals' Views on Sexual Information Following MI. British Journal of Nursing, 19, 1052-1054. https://doi.org/10.12968/bjon.2010.19.16.78202

[44] Ivarsson, B., Fridlund, B. and Sjöberg, T. (2009) Information from Health Care Professionals about Sexual Function and Coexistence after Myocardial Infarction: A Swedish National Survey. Heart \& Lung. The Journal of Acute and Critical Care, 38, 330-335. https://doi.org/10.1016/j.hrtlng.2009.01.001

[45] Magnan, M. and Reynolds, K. (2006) Barriers to Addressing Patient Sexuality Concerns across Five Areas of Specialization. Clinical Nurse Specialist. The Journal for Advanced Nursing Practice, 20, 285-292. https://doi.org/10.1097/00002800-200611000-00009

[46] O’Donovan, K. (2012) Resuming Sexual Activity after Myocardial Infarction. British Journal of Cardiac Nursing, 7, 535-543. https://doi.org/10.12968/bjca.2012.7.11.535

[47] Ho, T. and Fernández, M. (2006) Patient's Sexual Health: Do We Care Enough? Journal of Renal Care, 32, 183-186. https://doi.org/10.1111/j.1755-6686.2006.tb00019.x

[48] Byrne, M., Doherty, S., McGee, H.M. and Murphy, A.W. (2010) General Practitioner Views about Discussing Sexual Issues with Patients with Coronary Heart Disease: A National Survey in Ireland. BMC Family Practice, 11, 40. https://doi.org/10.1186/1471-2296-11-40

[49] Magnan, M.A. and Norris, D.M. (2008) Nursing Students' Perceptions of Barriers to Addressing Patient Sexuality Concerns. Journal of Nursing Education, 47, 260-268. https://doi.org/10.3928/01484834-20080601-06

[50] Mick, J. (2007) Sexuality Assessment: 10 Strategies for Improvement. Clinical Journal of Oncology Nursing, 11, 671-675. https://doi.org/10.1188/07.CJON.671-675

[51] Taylor, A. and Gosney, M.A. (2011) Sexuality in Older Age: Essential Considerations for Health Care Professionals. Age Ageing, 40, 538-543.

https://doi.org/10.1093/ageing/afr049

[52] Heath, H. (2011) Older People in Care Homes: Sexuality and Intimate Relationships. Nursing Older People, 23, 14-20.

https://doi.org/10.7748/nop2011.07.23.6.14.c8585

[53] Kong, S.K., Wu, L.H. and Loke, A.Y. (2009) Nursing Students' Knowledge, Attitude and Readiness to Work for Clients with Sexual Health Concerns. Journal of Clinical Nursing, 18, 2372-2382. https://doi.org/10.1111/j.1365-2702.2008.02756.x

[54] Buttaro, T.M., Koeniger-Donohue, R. and Hawkins, J. (2014) Feature Article: Sexuality and Quality of Life in Aging: Implications for Practice. The Journal for Nurse Practitioners, 10, 480-485. https://doi.org/10.1016/j.nurpra.2014.04.008

[55] Zeng, Y.C., Liu, X. and Loke, A.Y. (2012) Addressing Sexuality Issues of Women with Gynaecological Cancer: Chinese Nurses' Attitudes and Practice. Journal of Advanced Nursing, 68, 280-292. https://doi.org/10.1111/j.1365-2648.2011.05732.x

[56] Kim, S., Kang, H.S. and Kim, J. (2011) A Sexual Health Care Attitude Scale for 
Nurses: Development and Psychometric Evaluation. International Journal of Nursing Studies, 48, 1522-1532. https://doi.org/10.1016/j.ijnurstu.2011.06.008

[57] McCann, E. (2010) Investigating Mental Health Service User Views Regarding Sexual and Relationship Issues. Journal of Psychiatric and Mental Health Nursing, 17, 251-259. https://doi.org/10.1111/j.1365-2850.2009.01509.x

[58] Billington, T. (2012) Issues of Patient Sexuality in Nurse Education. British Journal of Nursing, 21, 1109. https://doi.org/10.12968/bjon.2012.21.18.1109

[59] Magnan, M.E., Reynolds, K.E. and Galvin, E. (2006) Barriers to Addressing Patient Sexuality in Nursing Practice. MEDSURG Nursing, 14, 282-289.

[60] Bal, M.D. and Sahiner, N.C. (2015) Turkish Nursing Students' Attitudes and Beliefs Regarding Sexual Health. Sexuality and Disability, 33, 223-231. https://doi.org/10.1007/s11195-014-9388-y

[61] Ayhan, H., Iyigun, E., Tastan, S. and Coskun, H. (2010) Turkish Version of the Reliability and Validity Study of the Sexual Attitudes and Belief Survey. Sexuality \& Disability, 28, 287-296. https://doi.org/10.1007/s11195-010-9157-5

[62] Southard, N.Z. and Jill Keller, M.S. (2009) The Importance of Assessing Sexuality: A Patient Perspective. Clinical Journal of Oncology Nursing, 13, 213. https://doi.org/10.1188/09.CJON.213-217

[63] Waltz, C., Strickland, O. and Lenz, E. (2014) Measurement in Nursing and Health Research. Springer, New York.

[64] Annon, J. (1976) The PLISSIT Model: A Proposed Conceptual Scheme for the Behavioural Treatment of Sexual Problems. Journal of Sex Education and Therapy, 2, 1 15.

[65] Randalla, G., Molloy, G.J. and Steptoe, A. (2009) The Impact of an Acute Cardiac Event on the Partners of Patients: A Systematic Review. Health Psychology Review, 3, 1-84. https://doi.org/10.1080/17437190902984919

[66] López-Medina, I.M., Gil-García, E., Sánchez-Criado, V. and Pancorbo-Hidalgo, P.L. (2016) Patients' Experiences of Sexual Activity Following Myocardial Ischemia. Clinical Nursing Research, 25, 45-66. https://doi.org/10.1177/1054773814534440

[67] Djurović, A., Marić, D., Brdareski, Z., Konstantinović, L., Rafajlovski, S., Obradović, S. and Mijailović, Z. (2010) Sexual Rehabilitation after Myocardial Infarction and Coronary Bypass Surgery: Why Do We Not Perform Our Job? Vojnosanitetski Pregled, 67, 579-587. https://doi.org/10.2298/VSP1007579D

[68] Steinke, E.E. and Jaarsma, T. (2015) Sexual Counseling and Cardiovascular Disease: Practical Approaches. Asian Journal of Andrology, 17, 32-39. https://doi.org/10.4103/1008-682X.135982

[69] Lange, R. and Levine, G. (2014) Sexual Activity and Ischemic Heart Disease. Current Cardiology Reports, 16, 1-9. https://doi.org/10.1007/s11886-013-0445-4

[70] Parish, S.J. and Rubio-Aurioles, E. (2010) Education in Sexual Medicine: Proceedings from the International Consultation in Sexual Medicine. Journal of Sextual Medicine, 7, 3305-3314. https://doi.org/10.1111/j.1743-6109.2010.02026.x 
Submit or recommend next manuscript to SCIRP and we will provide best service for you:

Accepting pre-submission inquiries through Email, Facebook, LinkedIn, Twitter, etc. A wide selection of journals (inclusive of 9 subjects, more than 200 journals)

Providing 24-hour high-quality service

User-friendly online submission system

Fair and swift peer-review system

Efficient typesetting and proofreading procedure

Display of the result of downloads and visits, as well as the number of cited articles Maximum dissemination of your research work

Submit your manuscript at: http://papersubmission.scirp.org/

Or contact health@scirp.org 